\title{
RETOS DEL ESTADO PERUANO COMO GARANTE DE LOS DERECHOS HUMANOS DE LA INFANCIA: EL DERECHO A LA IDENTIDAD DE LAS NIÑAS, NIÑOS Y ADOLESCENTES A PROPÓSITO DEL DECRETO LEGISLATIVO 1377
}

CHALLENGES OF THE PERUVIAN STATE AS GUARANTOR OF THE HUMAN RIGHTS OF CHILDREN: THE RIGHT TO THE IDENTITY OF GIRLS, CHILDREN AND ADOLESCENTS FOR THE PURPOSE OF LEGISLATIVE DECREE 1377

María Isabel Sokolich Alva*

Doctora en Derecho. Magíster en Derecho Civil con mención en Derecho de Familia. Fiscal Adjunto Supremo Titular de la Fiscalía Suprema Civil. Docente de la Academia de la Magistratura y de las Maestrías de Derecho Civil con mención en Derecho de Familia de la Universidad Femenina del Sagrado Corazón -UNIFE-, Maestría de Derecho de Familia y de la Persona de la Universidad Católica Santo Toribio de Mogrovejo y Maestría en Derecho Civil de la Universidad Pedro Ruiz Gallo. Expositora y Autora del libro "Violencia Familiar" y de diversos artículos jurídicos vinculados con el Derecho de Familia

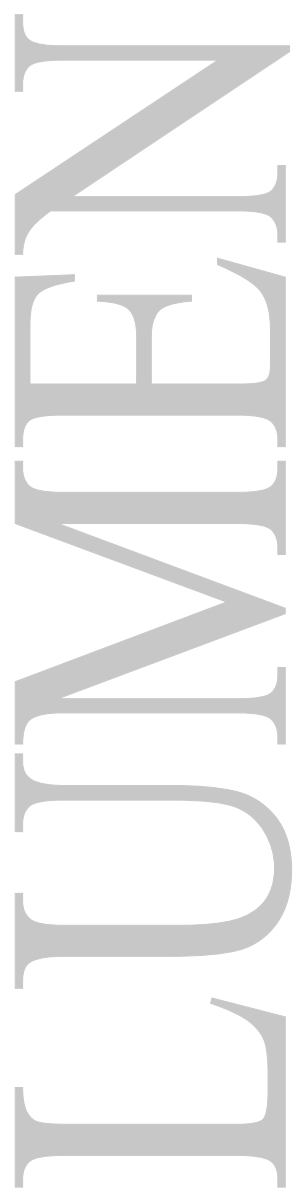




\title{
RETOS DEL ESTADO PERUANO COMO GARANTE DE LOS DERECHOS HUMANOS DE LA INFANCIA: EL DERECHO A LA IDENTIDAD DE LAS NIÑAS, NIÑOS Y ADOLESCENTES A PROPÓSITO DEL DECRETO LEGISLATIVO 1377
}

\author{
CHALLENGES OF THE PERUVIAN STATE AS GUARANTOR OF THE HUMAN RIGHTS OF \\ CHILDREN: THE RIGHT TO THE IDENTITY OF GIRLS, CHILDREN AND ADOLESCENTS FOR \\ THE PURPOSE OF LEGISLATIVE DECREE 1377
}

María Isabel Sokolich Alva

\begin{abstract}
RESUMEN
El reciente Decreto Legislativo 1377, que fortalece la protección integral de niñas, niños y adolescentes, representa un esfuerzo estatal por prevalecer el derecho del niño nacido en el matrimonio a gozar de una identidad acorde a la verdad biológica; si bien este hecho resulta relevante toda vez que legitima al padre biológico a reclamar la paternidad del hijo de mujer casada, la resolución del caso en concreto deberá sustentarse en el interés superior del niño.
\end{abstract}

\section{PALABRAS CLAVE:}

Derecho a la Identidad; Interés Superior del Niño; Derechos Fundamentales

\section{ABSTRACT}

The recent Legislative Decree 1377, which strengthens the comprehensive protection of children and adolescents, represents a state effort to prevail the right of the child born in marriage to enjoy an identity consistent with biological truth; Although this fact is relevant since it legitimizes the biological father to claim the paternity of the child of a married woman, the resolution of the specific case must be based on the best interests of the child.

\section{KEY WORDS:}

Right to Identity; Higher Interest of the Child; Fundamental Rights

\section{INTRODUCCIÓN:}

Con fecha 24 de agosto del 2018 se publicó en el Diario Oficial "El Peruano" el Decreto Legislativo 1377, cuya finalidad es "fortalecer la protección integral de niñas, niños y adolescentes, y garantizar el pleno ejercicio de sus derechos, priorizando las medidas de protección a su favor en situaciones de desprotección familiar, la optimización de servicios en situaciones de riesgo por desprotección familiar, su derecho a la identidad y al nombre, la reserva de su identidad y la de sus familiares ante casos de violencia, así como la priorización en el pago de las pensiones alimenticias determinadas a su favor en sentencias judiciales".

En lo que respecta al "derecho a la identidad", tema que nos avoca, debemos señalar que, en efecto, la norma representa un esfuerzo estatal por prevalecer el derecho del niño nacido en el matrimonio a gozar de una identidad acorde a la verdad biológica; con dicha intención se introducen las siguientes modificaciones legislativas:

$\checkmark \quad$ Se establece que el hijo (a) nacido durante el matrimonio o dentro de los trescientos (300) días calendario siguientes a su disolución tiene como padre al marido, salvo que la madre declare expresamente lo contrario. 
$\checkmark \quad$ El hijo o hija se presume matrimonial, salvo que la madre declare expresamente que no es del marido.

$\checkmark \quad$ El hijo o hija de mujer casada puede ser reconocido por su progenitor cuando la madre haya declarado expresamente que no es de su marido.

$\checkmark$ Dicho reconocimiento se puede realizar durante la inscripción del nacimiento cuando la madre y el progenitor acuden al registro civil, o con posterioridad a la inscripción realizada solo por la madre, cuando esta haya declarado quién es el progenitor; igualmente procede cuando el marido lo hubiese negado y obtenido sentencia favorable.

$\checkmark \quad$ La paternidad extramatrimonial puede ser judicialmente declarada, entre otros: (...) cuando se acredita el vínculo parental entre el presunto padre y el hijo o hija a través de la prueba de ADN u otras pruebas genéticas o científicas con igual o mayor grado de certeza.

Como es de apreciar, la madre (mujer casada) asume especial protagonismo toda vez que de ella dependerá el mantenimiento de la presunción de paternidad matrimonial o su quebrantamiento; ello, sin perjuicio de que sea el propio padre biológico quien directamente reclame en instancia judicial su paternidad.

Sea uno u otro el escenario, lo cierto y verdadero es que la resolución de un caso en concreto deberá sustentarse, más allá del dato biológico, en el "interés superior del niño", esto es, en lo que le resulte más beneficioso, por cuanto la individualidad del ser humano se construye sobre la base de un cúmulo de atributos y características que, sumados al origen biológico, coadyuvan a que se nos reconozca como únicos e irrepetibles.

Efectuadas estas precisiones, a continuación procederemos a examinar aspectos vinculados al derecho humano, por tanto, derecho fundamental, a la identidad de las niñas, niños y adolescentes.

\section{LOS DERECHOS FUNDAMENTALES DE LOS NIÑOS, NIÑAS Y ADOLESCENTES:}

Los Derechos Fundamentales constituyen un límite para el Estado y son el sustento de toda democracia; en pocas palabras, "(...) son el basamento moral mínimo que da origen a la organización política de la sociedad. (García, 1998). La referencia a derechos fundamentales implica la noción de dignidad humana, pues provienen de la naturaleza misma del ser humano.

Al respecto el Tribunal Constitucional Peruano, señala lo siguiente:

“(...) El concepto de derechos fundamentales comprende "tanto los presupuestos éticos como los componentes jurídicos, significando la relevancia moral de una idea que compromete la dignidad humana y sus objetivos de autonomía moral, y también la relevancia jurídica que convierte a los derechos en norma básica material del Ordenamiento, y es instrumento necesario para que el individuo desarrolle en la sociedad todas sus potencialidades. Los derechos fundamentales expresan tanto una moralidad básica como una juridicidad básica." (Peces-Barba, Gregorio. Curso de Derechos Fundamentales. Teoría General. Madrid: Universidad Carlos III de Madrid. Boletín Oficial del Estado, 1999, pág. 37).

Consecuentemente, si bien el reconocimiento positivo de los derechos fundamentales (comúnmente, en la Norma Fundamental de un ordenamiento) es presupuesto de su exigibilidad como límite al accionar del Estado y de los propios particulares, también lo es su connotación ética y axiológica, en tanto manifiestas concreciones positivas del principio- 
derecho de dignidad humana, preexistente al orden estatal y proyectado en él como fin supremo de la sociedad y del Estado (artículo $1^{\circ}$ de la Constitución). (...)"1

Para referirnos a los derechos fundamentales de los niños, niñas y adolescentes ${ }^{2}$, es menester señalar, prima facie, que la "Convención sobre los Derechos del Niño", adoptada en el seno de la Asamblea General de la Naciones Unidas el 20 de noviembre de $1989^{3}$, constituye un instrumento internacional vinculante para los Estados que la han suscrito y ratificado; su sustento es la denominada "Doctrina de la Protección Integral" que reconoce al niño un conjunto de derechos civiles, culturales, económicos, políticos y sociales en atención a cuatro principios fundamentales: derecho a la vida, la supervivencia y desarrollo, no discriminación, derecho de opinión e interés superior del niño.

Dicha Convención es la máxima expresión de un corpus juris ${ }^{4}$ internacional de protección de los derechos de los niños; en ese sentido, la Corte Interamericana de Derechos Humanos ${ }^{5}$ ha puntualizado que éste "(...) es el resultado de la evolución del Derecho Internacional de los Derechos Humanos en materia de niñez que tiene como eje el reconocimiento del niño y la niña como sujeto de derecho. Por tanto, el marco jurídico de protección de los derechos humanos de los niños no se limita a la disposición del artículo 19 de la Convención Americana, sino que incluye para fines de interpretación, entre otras, las disposiciones comprendidas en las declaraciones sobre los Derechos del Niño de 1924 y 1959, la Convención sobre los Derechos del Niño de 1989, las Reglas Mínimas de las Naciones Unidas para la Administración de Justicia de Menores (Reglas de Beijing de 1985), las Reglas sobre Medidas No Privativas de la Libertad (Reglas de Tokio de 1990) y las Directrices de las Naciones Unidas para la Prevención de la Delincuencia Juvenil (Reglas de Riad de 1990) además de los instrumentos internacionales sobre derechos humanos de alcance general".

Acontinuación, nos referiremos brevemente a los derechos específicos del niño, el reconocimiento del niño como sujeto de derechos y el principio del interés superior del niño.

\subsection{DERECHOS ESPECÍFICOS DEL NIÑO:}

La Convención parte por declarar que conforme a la Carta de las Naciones Unidas, la libertad, la justicia y la paz se basan en el reconocimiento de la dignidad intrínseca y de los derechos iguales e inalienables de todos los miembros de la familia humana, entre ellos, los niños.

Ahora bien, los derechos específicos e inalienables de los niños son pasibles de ser clasificados en 04 categorías: derechos civiles, derechos sociales, derechos culturales y derechos económicos; los que en nuestra realidad se encuentran plasmados en los Capítulos I y II del Libro I del Código de los Niños y Adolescentes.

Como derechos civiles se reconoce el derecho de todo niño a la vida e integridad, a recibir atención del Estado desde su concepción, a vivir en un ambiente sano, a la libertad, a la identidad, a vivir en una familia, a la libertad de opinión, a la libertad de expresión, a la libertad de pensamiento, conciencia y religión, al libre tránsito, y, a asociarse.

En la categoría de derechos económicos, sociales y culturales se distingue el derecho a la educación, cultura, deporte y recreación, a modalidades y horarios adecuados para el trabajo, así como la atención integral de salud.

Fundamento jurídico $2 .^{\circ}$ de la sentencia recaída en el Exp. N. ${ }^{\circ}$ 1417-2005-AA/TC

En adelante nos referiremos a ellos como "niño o niños".

Suscrita por el Perú el 26 de enero de 1990, aprobada por Resolución Legislativa № 25278, de fecha 03 de agosto de 1990, publicada en el diario oficial "El Peruano" el 04 de agosto de 1990.

4 Corpus juris en materia de niñez significa el reconocimiento a la existencia de un conjunto de normas fundamentales que se encuentran vinculadas con el fin de garantizar los derechos humanos de los niños, niñas y adolescentes.

5 Recuperado de: http://cidh.oas.org/countryrep/Infancia2sp/Infancia2cap1.sp.htm 
El Capituló III del Libro I regula el reconocimiento de los derechos de los niños y adolescentes discapacitados en base al postulado de no discriminación e igualdad de oportunidades en la comunidad.

\subsection{EL RECONOCIMIENTO DEL NIÑO COMO SUJETO DE DERECHOS:}

Se funda en el hecho de considerar al "niño" como "persona humana", lo que posibilita admitir la igualdad de derechos en relación a los demás y el reconocimiento de derechos específicos.

Por el reconocimiento del niño como sujeto de derechos se propugna “(...) el reconocimiento del rol activo de éste frente a su realidad. De su capacidad para contribuir al desarrollo propio, al de su familia y al de su comunidad. Y lo incorpora en la construcción de la aplicabilidad de la Convención como auténtico promotor de cambio y desarrollo. Por ello pone en cuestión la arbitraria y fundamentalmente cronológica división social entre niños y adultos que normalmente se asume y expresa, por ejemplo en la simple capacidad de acceso a su cédula de identidad (...)" (Elideso, 2002).

A decir de Miguel Cillero Bruñol ${ }^{6}$, la titularidad de derechos lleva inmersa tres implicancias: el derecho a tener derechos, el carácter exigible de dichos derechos y el nuevo lugar y rol de los niños, niñas y adolescentes en las relaciones familiares, sociales y con el Estado.

Resulta importante enfatizar que la capacidad de ejercicio de un niño, con las limitaciones establecidas por la Ley ${ }^{7}$, se viabiliza con la ratificación de su condición de sujeto de derechos. La Convención consagra dicho reconocimiento en los artículos $10 .^{\circ}, 12 .^{\circ}, 13 .^{\circ}, 14 .^{\circ}, 15 .^{\circ}, 19 .^{\circ}$ y $22 .^{\circ}, l_{0}$ que a su vez es recogido por el artículo II del Título Preliminar Código de los Niños y Adolescentes del Perú ${ }^{8}$, expresado, entre otros, en el derecho a la libertad de opinión, expresión, pensamiento, conciencia y religión, libre tránsito y asociación, a que se refieren los artículos $9 .^{\circ}, 10 .^{\circ}, 11 .^{\circ}, 12 .^{\circ}$ y $13 .^{\circ}$, respectivamente.

\subsection{EL PRINCIPIO DEL INTERÉS SUPERIOR DEL NIÑO:}

El Principio del Interés Superior del Niño constituye la máxima rectora de la doctrina de la "Protección Integral", de allí que debe constituir el sustento de todos los temas que involucren a los derechos e intereses de la infancia.

El calificativo de "superior" apunta a que el niño es un sujeto de derechos al que se le debe garantizar la protección y satisfacción de su necesidades en armonía con las del núcleo familiar; no obstante, muchas veces resulta imposible la armonización de los intereses encontrados, en cuyo caso a tenor de lo dispuesto por la Convención debe prevalecer el interés del infante.(Martínez, 2002).

El principio del interés superior del niño actúa como un límite a la actuación de la autoridad estatal, legislativa, judicial y administrativa; Miguel Cillero Bruñol (1998), refiere que "el ejercicio de la autoridad, cualquiera que sea su naturaleza jurídica se orienta y limita por los derechos que el ordenamiento jurídico le reconoce al niño, considerando además los principios de autonomía progresiva del niño en el ejercicio de sus derechos y de participación en todos los asuntos que le afecten. En este sentido, se puede afirmar que el principio puede ser concebido como un límite al paternalismo estatal y que puede orientar hacia soluciones no autoritarias en aquellas situaciones difíciles en las que el conflicto entre

6 Citado por Hernán Restrepo. Mesa "Niños, niñas y adolescentes sujetos de derechos" como aporte de la Mesa de Participación para el acercamiento al concepto: sujeto de derechos. REDANI 2007.

7 El artículo $46^{\circ}$ del Código Civil, modificado por Ley $N^{\circ} 29274$, prevé que tratándose de mayores de catorce años cesa la incapacidad a partir del nacimiento del hijo para realizar los siguientes actos: 1. Reconocer a sus hijos. 2. Demandar por gastos de embarazo y parto. 3. Demandar y ser parte en los procesos de tenencia y alimentos a favor de sus hijos. 4. Demandar y ser parte en los procesos de filiación extramatrimonial de sus hijos.

8 Artículo II.- Sujeto de derechos.- El niño y el adolescente son sujetos de derechos, libertades y de protección específica. Deben cumplir las obligaciones consagradas en esta norma. 
derechos del niño exige utilizar una regla compleja para la construcción de una decisión que proteja efectivamente los derechos amenazados o vulnerados (...)".

A nivel nacional, la Constitución Política del Perú por el artículo $4 .^{\circ}$ prevé que "La comunidad y el Estado protegen especialmente al niño, al adolescente, a la madre y al anciano en situación de abandono. También protegen a la familia y promueven el matrimonio. Reconocen a estos últimos como institutos naturales y fundamentales de la sociedad".

El dispositivo constitucional no hace más que ratificar la obligación primera del Estado de proteger al niño, entendiéndose como tal incluso al concebido, conforme lo estipulado por el numeral 2) del artículo $2 .^{\circ}$ de la Carta Fundamental ${ }^{9}$ y el artículo $1 .^{\circ}$ del Título Preliminar del Código de los Niños y Adolescentes, en atención a su condición de persona humana demandante de especial cuidado y protección, tanto para la satisfacción de sus necesidades vitales, como para el logro de su realización integral.

La norma en modo alguno, desconoce o niega el deber, a la vez derecho, legal y biológico de los padres de alimentar, educar y dar seguridad a sus hijos ${ }^{10}$, como manifestación expresa del ejercicio de la responsabilidad parental ${ }^{11}$, sino, que determina el rol preponderante del Estado en la protección de los derechos del niño a través de políticas públicas específicas orientadas a coadyuvar a su bienestar, lo que incluye aspectos de alimentación, salud, educación, vivienda, entre otros. Debemos recordar, que ante la muerte o ausencia de los padres o el incumplimiento de los roles parentales, el Estado tiene la obligación de cautelar la integridad de los niños mediante la adopción de medidas de protección acorde al procedimiento a que se refiere el Decreto Legislativo N. ${ }^{0} 1297^{12}$.

En relación al tema, el Tribunal Constitucional ha establecido como "doctrina jurisprudencial vinculante" lo siguiente:

〉> "El principio constitucional de protección del interés superior del niño, niña y adolescente presupone que los derechos fundamentales del niño, niña y adolescente, y en última instancia su dignidad, tienen fuerza normativa superior no sólo en el momento de la producción de normas, sino también en el momento de la interpretación de ellas, constituyéndose por tanto en un principio de ineludible materialización para el Estado, la sociedad en su conjunto y la propia familia, incluidos claro está el padre, la madre o quien sea el responsable de velar por sus derechos fundamentales"13.

Es importante señalar que la Observación General N. ${ }^{\circ} 14$ del Comité de los Derechos del Niño (2013) establece que el "principio del interés superior del niño" no es un concepto o una directriz

9 Artículo 2.- Derechos fundamentales de la persona Toda persona tiene derecho: (...) 1. A la vida, a su identidad, a su integridad moral, psíquica y física y a su libre desarrollo y bienestar. El concebido es sujeto de derecho en todo cuanto le favorece.

10 Artículo 6.- La política nacional de población tiene como objetivo difundir y promover la paternidad y maternidad responsables. Reconoce el derecho de las familias y de las personas a decidir. En tal sentido, el Estado asegura los programas de educación y la información adecuados y el acceso a los medios, que no afecten la vida o la salud. Es deber y derecho de los padres alimentar, educar y dar seguridad a sus hijos. Los hijos tienen el deber de respetar y asistir a sus padres. Todos los hijos tienen iguales derechos y deberes. Está prohibida toda mención sobre el estado civil de los padres y sobre la naturaleza de la filiación en los registros civiles y en cualquier otro documento de identidad.

11 Artículo 74.- Son deberes y derechos de los padres que ejercen la Patria Potestad: a) Velar por su desarrollo integral; b) Proveer su sostenimiento y educación; c) Dirigir su proceso educativo y capacitación para el trabajo conforme a su vocación y aptitudes; d) Darles buenos ejemplos de vida y corregirlos moderadamente. Cuando su acción no bastare podrán recurrir a la autoridad competente; e) Tenerlos en su compañía y recurrir a la autoridad si fuere necesario para recuperarlos; f) Representarlos en los actos de la vida civil mientras no adquieran la capacidad de ejercicio y la responsabilidad civil; g) Recibir ayuda de ellos atendiendo a su edad y condición y sin perjudicar su atención; h) Administrar y usufructuar sus bienes, cuando los tuvieran; y i) Tratándose de productos, se estará a lo dispuesto en el Artículo 1004 del Código Civil.

12 Protección de niñas, niños y adolescentes sin cuidados parentales o en riesgo de perderlos.

13 Fundamento jurídico $19^{\circ}$ de la sentencia recaída en el Exp. № 04058 2012-PA/TU. 
vaga, sin contenido; sino que debe ser entendido como un triple concepto (derecho sustantivo, principio de interpretación fundamental y norma de procedimiento), toda vez que su objetivo es garantizar el desarrollo holístico del niño

A nivel nacional, con la promulgación de la Ley N 30466, (nueva Ley que fija parámetros para garantizar el ISN) por primera vez se establecen en el país parámetros y garantías procesales para la consideración primordial del interés superior del niño acorde a lo establecido por la Observación General N ${ }^{\circ} 14$ del Comité de los Derechos del Niño, las cuales obligatoriamente deben ser observadas por la justicia especializada.

\section{EL DERECHO FUNDAMENTAL A LA IDENTIDAD:}

Se encuentra previsto por el artículo $2^{\circ}$ numeral 1 ) de la Constitución Política del Perú y en esencia es "(...) el derecho que tiene todo individuo a ser reconocido estrictamente por lo que es y por el modo como es. Vale decir, el derecho a ser individualizado conforme a determinados rasgos distintivos, esencialmente de carácter objetivo (nombres, seudónimos, registros, herencia genética, características corporales, etc.) y aquellos otros que se derivan del propio desarrollo y comportamiento personal, más bien de carácter subjetivo (ideología, identidad cultural, valores, reputación, etc.). 3. La identidad desde la perspectiva descrita no ofrece, pues, como a menudo se piensa, una percepción unidimensional sustentada en los elementos estrictamente objetivos o formales que permiten individualizar a la persona. Se encuentra, además, involucrada con una multiplicidad de supuestos que pueden responder a elementos de carácter netamente subjetivos, en muchos casos, tanto o más relevantes que los primeros. Incluso algunos de los referentes ordinariamente objetivos no sólo pueden ser vistos simultáneamente, desde una perspectiva subjetiva, sino que eventualmente pueden ceder paso a estos últimos o simplemente transformarse como producto de determinadas variaciones en el significado de los conceptos. 4. Queda claro que cuando una persona invoca su identidad, en principio lo hace para que se la distinga frente a otras. Aun cuando a menudo tal distinción pueda percibirse con suma facilidad a partir de datos tan elementales como el nombre o las características físicas (por citar dos ejemplos), existen determinados supuestos en que tal distinción ha de requerir de referentes mucho más complejos, como puede ser el caso de las costumbres o las creencias (por citar otros dos casos). El entendimiento de tal derecho, por consiguiente, no puede concebirse de una forma inmediatista, sino necesariamente de manera integral, tanto más cuando de por medio se encuentran planteadas discusiones de fondo en torno a la manera de identificar del modo más adecuado a determinadas personas". (énfasis agregado)

En materia de infancia y adolescencia, se encuentra reconocido en forma expresa en el artículo $8^{\circ}$ de la Convención sobre los Derechos del Niño y el artículo $6^{\circ}$ del Código de los Niños y Adolescentes, según el cual este derecho comprende a la vez el derecho del niño a gozar de un nombre, a adquirir una nacionalidad y en la medida de lo posible a conocer a sus padres y llevar sus apellidos.

El derecho a la identidad se materializa en una doble faceta, esto es: a) estática, que alude al sexo, fenotipo, nombre, herencia genética, etc; $y, b$ ) dinámica, expresada en el conjunto de atributos, hábitos, costumbres, valores, reputación, normas de conducta, etc, de la persona.

En orden a lo expresado, la identidad de una persona no puede concebirse ni reconocerse únicamente en atención a una de sus manifestaciones con exclusión de la otra, sino que merece un análisis integral que responda a dos interrogantes: ¿quién es? y ¿cómo es? la persona, lo que sin dudas realizará este y otros derechos conexos, como la integridad, dignidad de la persona, el derecho a crecer y desarrollarse en una familia, etc.

Conforme se señala en la Casación N. ${ }^{\circ}$ 950-2016, Arequipa, la protección jurídica del derecho a la identidad en su calidad de derecho humano esencial debe ser integral, para comprender los 
múltiples y complejos aspectos de la personalidad de un ser humano; el derecho a la identidad de un niño debe concebirse en atención al interés superior de aquel, más no a favor de los intereses de sus padres ${ }^{14}$.

En consonancia con lo reseñado, consideramos que la plena realización del derecho fundamental a la identidad de todo niño exige al operador jurídico ponderar la esencia de este derecho en forma integral, esto es, tanto desde su fase estática como dinámica, por cuanto la persona humana no se identifica e individualiza así misma y ante los demás en razón única del dato biológico, sino, que ello obedece a la conjunción de ambas facetas de la identidad que coadyuvan a reconocernos como seres únicos e irrepetibles.

\subsection{EL DERECHO A LA IDENTIDAD EN LA PRAXIS JUDICIAL:}

\section{CASACIÓN 4430-2015 HUAURA:}

Las particularidades del caso son las siguientes:

- El actor interpone demanda de Impugnación de Paternidad de una niña a quien reconoció como hija extramatrimonial en el año 2004; sostiene, que la emplazada en forma reiterada le manifestó que no era el padre biológico, por lo cual solicitó al Hospital de Barranca la hoja de identificación de la niña, advirtiendo que en ella se consignaba el nombre de otra persona como padre.

Igualmente, refiere que en el proceso de prueba anticipada la demandada no concurrió a la Audiencia de Actuación y Declaración Judicial, frustrándose la diligencia de tomas de muestras para la realización de la prueba de ADN, por lo que dicha conducta debe tenerse en cuenta al momento de sentenciar.

- Mediante sentencia de primera instancia se declaró FUNDADA la demanda, la cual al ser apelada fue CONFIRMADA por la instancia superior.

- La Sala Suprema declaró FUNDADO el recurso de casación, NULA la sentencia de vista; y, actuando en sede de instancia, REVOCÓ la resolución que declaró FUNDADA la demanda y REFORMÁNDOLA la declaró IMPROCEDENTE en mérito de los siguientes argumentos:

a) Que, la niña fue reconocida libremente por el demandante.

b) Que, dicha filiación otorga una identidad que, en primera instancia, podemos llamar estática, pero que luego se irá realizando en el acontecer diario de una manera dinámica y proyectiva.

c) Que, el derecho a la identidad, conforme lo puntualizado por el doctor Carlos Fernández Sessarego constituye "El conjunto de atributos y características que permiten individualizar la persona en sociedad", presentándose bajo dos aspectos: "uno estático, mediante el cual se da una primera e inmediata visión del sujeto (nombre, seudónimo, características físicas y documentarias) y un aspecto dinámico constituido por la suma de pensamientos, opiniones, creencias, aptitudes, comportamientos de cada persona que se explaya en el mundo de la intersubjetividad".

d) Que, cuando se objeta la identidad de una persona se tiene que valorar tanto el cariz estático como el dinámico del referido derecho fundamental; es decir, cuando se impugna la paternidad de una persona, ello no puede justificarse solo en el dato genético, pues ello implicaría olvidar

14 Considerando segundo. 
que el ser humano se hace a sí mismo en el proyecto continuo que es su vida. Más allá de los datos fijos, es la propia historia del individuo lo que lo hace idéntico a sí mismo.

e) Que, es en ese contexto, que el pedido del recurrente no puede admitirse porque se ampara solo en probables supuestos genéticos, teniendo como base afirmaciones de la demandada (madre de la menor) que le ha manifestado no ser el padre; realizando su impugnación en el año dos mil diez, no obstante haberla reconocido en el año dos mil cuatro. Para casos como estos resultan de la aplicación los artículos $399^{\circ}$ y $400^{\circ}$ del Código Civil, dado que interesa tanto al Estado (que necesita saber con certeza la identidad de una persona) como al particular (que ha labrado su identidad dinámica con la certeza de conocer a su padre) que haya un punto de cierre para la impugnación de la paternidad.

f) Que, amparar la demanda significaría que los tribunales de justicia fomenten la impugnación de paternidad por motivos irrelevantes, generando un estado de incertidumbre absoluta sobre la identidad de las personas.

La sentencia casatoria confirma una posición que se va fortaleciendo cada vez más en la administración de justicia ${ }^{15}$, según la cual la identidad de un niño debe garantizarse en atención a la valoración de la verdad biológica en conjunción con lo que más favorezca a ese niño; esto es, su interés superior, de tal forma que la opinión del niño, la afectividad entre el padre legal, el padre biológico y el hijo, la noción de familia, los vínculos familiares desplegados, entre otros, se tomen en cuenta al momento de dilucidar un caso de impugnación de paternidad.

La observancia de estos parámetros los encontramos de manifiesto en la Casación N. ${ }^{\circ}$ 9502016. Arequipa, a la cual hiciéramos referencia en forma antelada, cuando al resolver la justicia prefirió mantener la filiación matrimonial entre el marido y la hija matrimonial, a pesar que la verdad biológica le daba razón al demandante.

En suma, el derecho fundamental a la identidad de un niño corresponde ser realizado en forma integral por el Estado, y, en su caso, por los operadores jurídicos, de tal forma que por encima de los intereses de las partes, el interés superior del niño sea el que prevalezca.

\section{CONCLUSIONES}

El Estado peruano como garante de los derechos humanos de la infancia tiene el deber de respetar, proteger y realizar, en forma real y concreta, los derechos y garantías de las niñas, niños y adolescentes del país, entre estos, a gozar de su verdadera identidad, conforme así lo consagra el artículo $8 .^{\circ}$ de la Convención, razón por la cual la ponderación efectuada por el legislador con la promulgación del Decreto Legislativo $\mathrm{N} .^{\circ} 1377$ a fin de favorecer la identidad sobre la presunción de paternidad matrimonial resulta en consonancia con el referido compromiso estatal.

La plena realización del derecho fundamental a la identidad de un niño exige al operador jurídico sopesar responsablemente la esencia del derecho a la identidad en forma integral, esto es, tanto desde su fase estática como dinámica, por cuanto la persona humana no se identifica e individualiza a sí misma en razón única del dato biológico, sino, que es la conjunción de ambos aspectos la que determina su singularidad, hecho que cobra mayor relevancia cuando del proyecto de vida de un niño se trata.

\section{REFERENCIAS}

- CILleRo BRUÑOL, Miguel (1998). El Interés Superior del Niño en el Marco de la Convención Internacional sobre los Derechos del Niño. En García Méndez, Emilio,

15 Revisar también la Casación Nº 3797-2012-Arequipa. 
Infancia, ley y democracia en América Latina. Análisis crítico del panorama legislativo en el marco de la Convención Internacional sobre los Derechos del Niño (1990-1998), Bogotá: Ed. Temis-Depalma.

- $\quad$ ELIDESO SOLARI, Néstor (2002). La Niñez y sus Nuevos Paradigmas. Buenos Aires.

- GARCía tOMA, Víctor (1998). Análisis sistemático de la Constitución Peruana de 1993. Lima: Fondo Editorial de la Universidad de Lima.

- MARTíNEZ RUIZ, Analía (2002). Interés Superior" en "La Convención sobre los Derechos del Niño". Editorial Rubinzal-Culzon

Fecha de recepción: 30 de abril de 2018

Fecha de aceptación: 16 de junio de 2018 